06;07

\title{
Механизмы частотно-зависимой проводимости мезопористого кремния при гамма-облучении малыми дозами
}

\author{
(C) В.В. Галушка ${ }^{1}$, Э.А. Жаркова ${ }^{1}$, Д.В. Терин ${ }^{1,2, \uparrow, ~ В . И . ~ С и д о р о в ~}{ }^{1}$, Е.И. Хасина ${ }^{1}$ \\ ${ }^{1}$ Саратовский национальный исследовательский государственный университет им. Н.Г. Чернышевского, Саратов, Россия \\ ${ }^{2}$ Саратовский государственный технический университет им. Гагарина Ю.А., Саратов, Россия \\ ฯE-mail: lab32@mail.ru
}

Поступило в Редакцию 26 ноября 2018 г. В окончательной редакции 6 марта 2019 г. Принято к публикации 7 марта 2019 г.

\begin{abstract}
Исследовано влияние гамма-излучения малых доз на механизмы низкочастотной проводимости мезопористого кремния. Показано, что при гамма-облучении сохраняется прыжковый характер проводимости с изменением частоты фононных колебаний решетки, уменьшением размера прыжка и сдвигом уровня захвата ловушек к уровню Ферми в запрещенной зоне, что делает структуры с мезопористым кремнием, облученные гамма-излучением, перспективными для создания многофункциональных резистивных и емкостных приборов.
\end{abstract}

Ключевые слова: мезопористый кремний, гамма-облучение, прыжковая проводимость, фононная частота, колебания решетки.

DOI: 10.21883/PJTF.2019.11.47814.17607

Исследования влияния гамма-излучения на свойства пористого кремния были направлены в основном на изучение радиационной стойкости и выяснение природы фотолюминесценции [1]. Эффект влияния гамма-излучения на структуру пористого кремния, выражающийся в уменьшении пористости, рассмотрен в работе [2]. Проведенные ранее исследования $[3,4]$ влияния гамма-облучения малыми дозами на электрические и емкостные характеристики структур на основе мезопористого кремния (SiMP) показали, что при облучении SiMP происходит увеличение проводимости и уменьшение концентрации поверхностных заряженных оборванных связей. Однако сам механизм частотной зависимости проводимости не был выявлен, в то время как знать его необходимо для изучения электронных процессов в материалах при гамма-облучении и возможности создания приборов с управляемой реактивностью на основе структур с SiMP.

Настоящая работа посвящена определению характера частотной зависимости проводимости мезопористого кремния при гамма-облучении малыми дозами. Для этого необходимо знать емкость и добротность исследуемых структур в области низких частот $\left(10^{2}-10^{7} \mathrm{~Hz}\right)$, в которой проявляются особенности электродинамических процессов в неупорядоченных средах [5].

Исследовались структуры на основе мезопористых слоев кремния $\mathrm{Al}-\mathrm{SiMP}-p^{+}-\mathrm{Si}-\mathrm{Al}$, в которых слои SiMP были получены методом химического травления кремния с использованием металлов в водном растворе $\mathrm{AgNO}_{3}$ на кремниевых подложках $p$-типа с удельным сопротивлением $4.5 \Omega \cdot \mathrm{cm}$. Технология получения структур $\mathrm{Al}-\mathrm{SiMP}-p^{+}-\mathrm{Si}-\mathrm{Al}$ описана ранее [3]. Образцы были получены в одинаковом технологическом режиме, но в нем возможны незначительные колебания технологических факторов, которые, вероятно, приводят к более тонкому влиянию на структуру слоев [6]. Для облучения полученных структур применялся пучок гамма-квантов тормозного излучения бетатрона Саратовского государственного университета при максимальной энергии $E_{\gamma \max }=25 \mathrm{MeV}$. Экспозиционная доза $D$ менялась от 5 до $20 \mathrm{kR}$.

Результаты измерения частотных зависимостей емкости $C(f)$ и тангенса угла диэлектрических потерь $\operatorname{tg} \delta(f)$ приведены на рис. 1,2 . По характеру экспериментальных частотных зависимостей $C(f)$ и $\operatorname{tg} \delta(f)$ образцы можно разделить на две группы. Группа I - облученные образцы, для которых наблюдается монотонный спад емкости и $\operatorname{tg} \delta$ с частотой (рис. 1,2 , кривые 1,2 ). При этом емкость в диапазоне частот выше $10^{4} \mathrm{~Hz}$ стабилизируется, и ее величина соответствует геометрической емкости слоя SiMP. Образцы группы II характеризуются большим диапазоном изменения емкости в зависимости от частоты: 10-50 раз (рис. 1, кривые 3-5), а также наличием минимума на зависимости $\operatorname{tg} \delta(f)$ в области частот $10^{3}-10^{4} \mathrm{~Hz}$ (рис. 2, кривые $3-5$ ). Минимум $\operatorname{tg} \delta(f)$ для этой группы наблюдается как у необлученных (рис. 2, кривая 3), так и у облученных гамма-лучами образцов. Положение минимума $\operatorname{tg} \delta(f)$ с облучением сдвигается в область больших частот (рис. 2, кривая 4). Уменьшение $\operatorname{tg} \delta(f)$ при $10^{4} \mathrm{~Hz}$ наблюдается у всех структур этой группы, что свидетельствует о снижении тока потерь. Подобную зависимость $\operatorname{tg} \delta(\omega)$ с минимумом при электронном облучении сильнолегированного кремния наблюдали авторы работ [7,8]. Для описания полученных зависимостей авторы подбирали эквивалентные схемы, включающие активные и реактивные составляющие сопротивления, и пришли к выводу о существовании прыжковой проводимости по глубоким энергетическим 


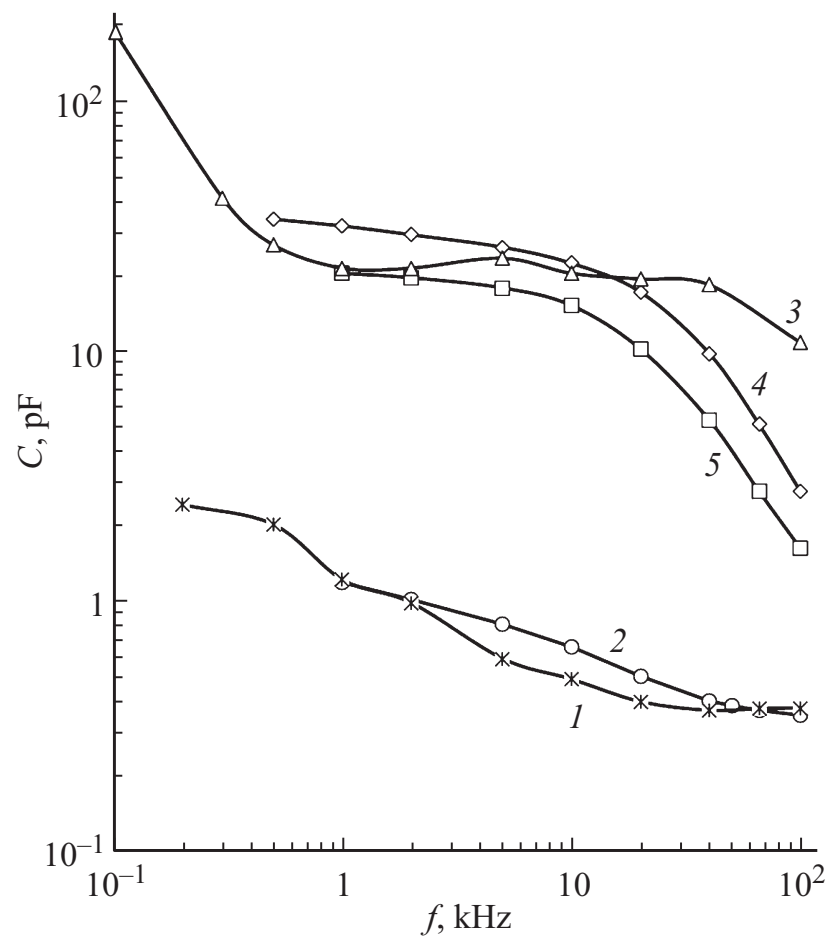

Рис. 1. Частотная зависимость емкости структуры $\mathrm{Al}-\mathrm{SiMP}-p^{+}-\mathrm{Si}-\mathrm{Al}$ при гамма-облучении. Экспозиционная доза $D=0(3), 20 \mathrm{kR}(1,2,4,5)$.

уровням. При этом электронное облучение и отжиг приводят к изменению величины и положения $\operatorname{tg} \delta(f)$.

По экспериментальным значениям емкости и $\operatorname{tg} \delta(f)$ для всех образцов рассчитывалась низкочастотная проводимость слоя SiMP согласно выражению

$$
\sigma(\omega)=\varepsilon^{\prime} \varepsilon_{0} \omega \operatorname{tg} \delta
$$

где $\omega=2 \pi f-$ круговая частота, $\varepsilon^{\prime}, \varepsilon_{0}-$ диэлектрические проницаемости слоя и вакуума.

Полученные зависимости проводимости от частоты приведены на рис. 3. Как видно, для образцов обеих групп характерен рост проводимости с частотой в области $\omega>10^{3} \mathrm{~s}^{-1}$ по степенному закону $\sigma \sim \omega^{s}$ при разных значениях $s$. Так, для образцов группы I $s \sim 0.4-0.6$ (кривые 1,2), а для образцов группы II $s>1$, при этом величина $s$ больше у облученных образцов $(\sim 1.4)$ (кривые 4,5$)$, чем у необлученного образца $(s \sim 1.1-1.2)$ (кривая 3).

Известно, что частотная проводимость зависит от частоты фононных колебаний решетки $v_{p h}$, концентрации заряженных состояний вблизи уровня Ферми $N\left(E_{\mathrm{F}}\right)$ и частоты переменного тока [5]:

$$
\sigma(\omega)=\frac{1}{3} \pi e^{2} k T \omega\left[N\left(E_{\mathrm{F}}\right)\right]^{2} \alpha^{-5}\left[\ln \left(\frac{v_{p h}}{\omega}\right)\right],
$$

где $a$ - размытие потенциальной ямы $\left(a^{-1}=8 \AA\right)$. Величина $s$ в зависимости $\ln \sigma(\omega)$ от $\ln \omega$ определяется выражением

$$
s=1-\frac{4}{\ln \left(\frac{v_{p h}}{\omega}\right)} \quad \text { для } \quad \omega \ll v_{p h} .
$$

Для образцов группы I величина $v_{p h} \sim 10^{8}-10^{10} \mathrm{~s}^{-1}$ при $s \sim 0.4-0.6$, что характеризует проводимость как прыжковую дебаевского типа по локализованным состояниям вблизи уровня Ферми. Таким образом, величина $v_{p h}$ в облученных образцах меньше, чем в монокремнии [5] и окисленном пористом кремнии ПКО [9], не подвергнутых облучению, где она составляет $10^{12} \mathrm{~s}^{-1}$ при $s \sim 0.8$. Это указывает на то, что изменение прыжковой проводимости дебаевского типа, а именно с переменной длиной прыжка, происходит за счет прыжков через случайные барьеры и других механизмов, например влияния поляризации оболочек ядер [10].

Используя полученные значения фононной частоты $v_{p h}$ при облучении, можно определить размер прыжка на переменном токе

$$
r_{\omega}=\frac{1}{2 a} \ln \left(\frac{v_{p h}}{\omega}\right) .
$$

Величина прыжка $r_{\omega}$ в случае образцов группы I при значениях $v_{p h} \sim 10^{8}-10^{10} \mathrm{~s}^{-1}$ на частоте $10^{4} \mathrm{~Hz}$ и $a^{-1}=8 \AA$ (размытие потенциальной ямы) для германия и кремния составляет 40-56 А в случае облученных образцов, в то время как в случае необлученных образцов, например окисленного пористого кремния, величины $r_{\omega}$ составляют 60-80 $[5,9]$.

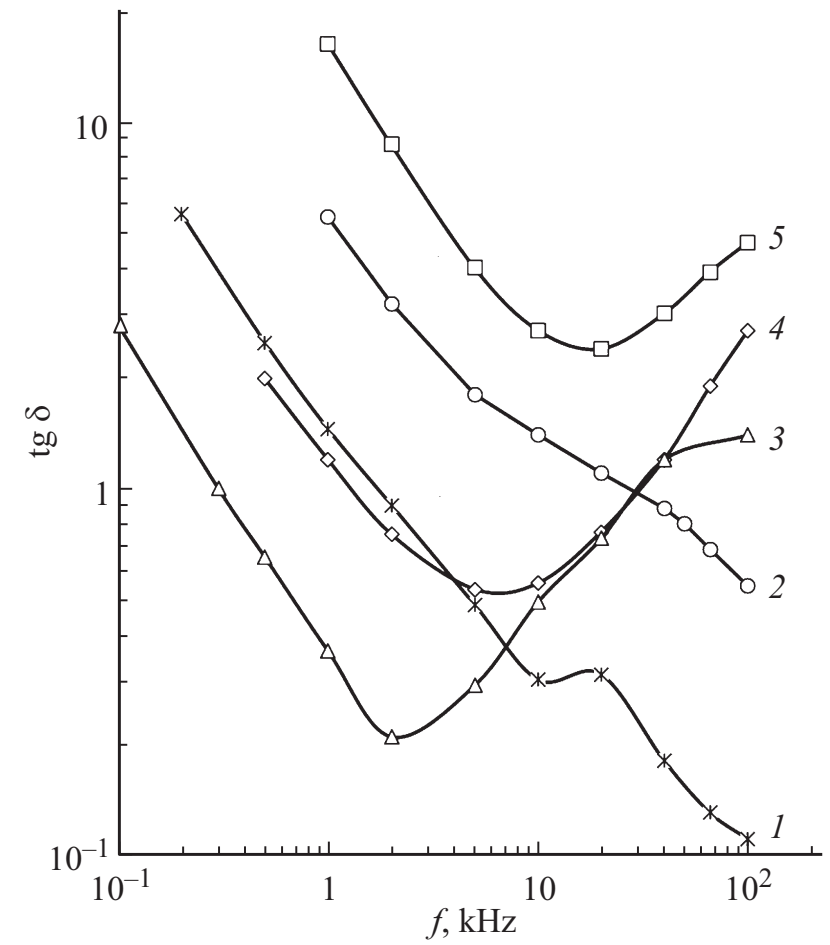

Рис. 2. Частотная зависимость тангенса угла диэлектрических потерь $(\operatorname{tg} \delta)$ структуры $\mathrm{Al}-\mathrm{SiMP}-p^{+}-\mathrm{Si}-\mathrm{Al}$ при гамма-облучении. Экспозиционная доза $D=0(3)$ и $20 \mathrm{kR}(1,2,4,5)$. 


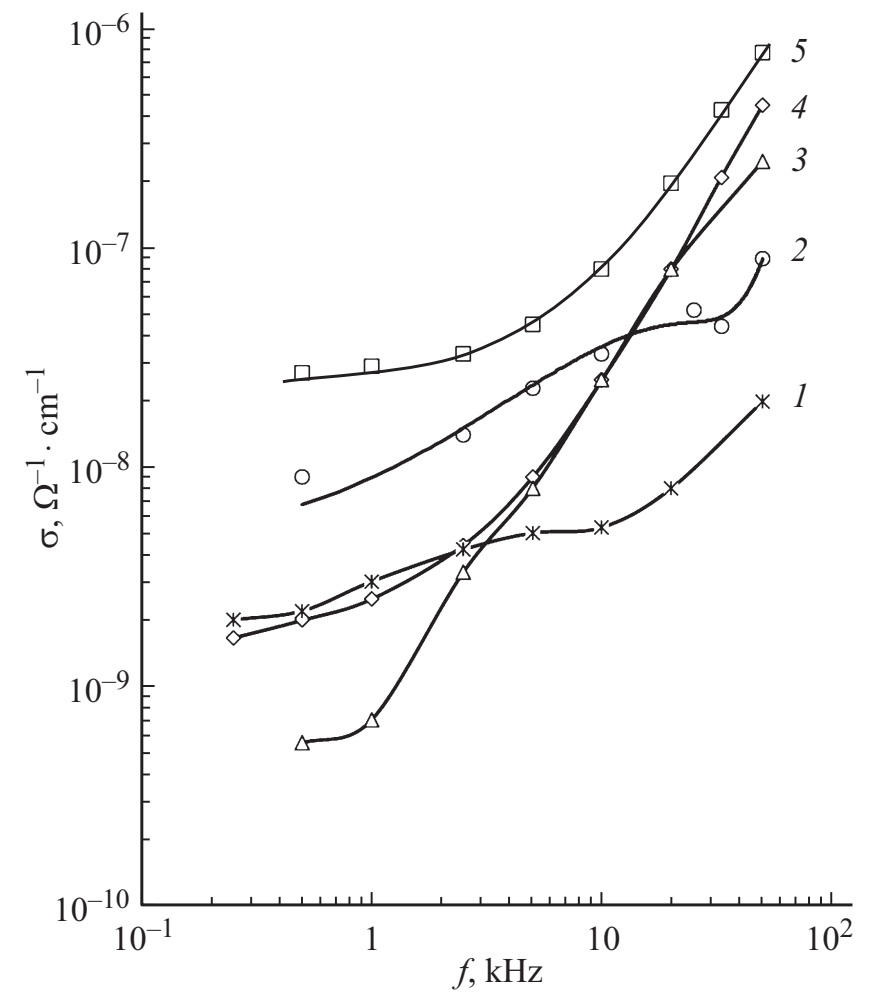

Рис. 3. Низкочастотная проводимость структуры $\mathrm{Al}-\mathrm{SiMP}-p^{+}-\mathrm{Si}-\mathrm{Al}$ при гамма-облучении. Экспозиционная доза $D=0$ (3) и $20 \mathrm{kR}(1,2,4,5)$.

Итак, длина прыжка с облучением уменьшается, что очевидно связано с изменением заряженных состояний, пассивацией заряженных центров и захватом и перекрытием оболочек ядер.

Большие значения $s$, полученные для образцов группы II, очевидно, связаны не только со свойствами слоя SiMP, но и со свойствами барьеров контактов Al-SiMP и гетероперехода $\mathrm{SiMP}-p^{+}-\mathrm{Si}$ и влиянием облучения на эти факторы, что было показано ранее [3].

Наличие минимума $\operatorname{tg} \delta$ позволяет определить время релаксации процесса. Процесс включает в себя преодоление электроном высоты барьера при прыжках между локализованными состояниями:

$$
\frac{1}{\tau}=v_{p h} \exp \left(-\frac{E_{a}}{k T}\right),
$$

где $\tau=1 / \omega_{\min }$.

При полученном сдвиге $\omega_{\min }$ при облучении от $2 \cdot 10^{3}$ до $7 \cdot 10^{3} \mathrm{~Hz}$ (рис. 2) изменение энергетического уровня составляет от 0.32 до $0.37 \mathrm{eV}$. Это значение близко к соответствующему энергетическому уровню в результате радиационных нарушений в германии [11].

Таким образом, показано, что для ряда образцов мезопористого кремния облучение приводит к изменению частоты фононных колебаний решетки и соответственно уменьшению длины прыжка, что связано, возможно, с деформацией решетки и ранее показанным влиянием гамма-облучения на структуру мезопористого кремния [3], перекрытием оболочек заряженных центров и сдвигом энергетических ловушек захвата к уровню Ферми.

Итак, гамма-облучение влияет на механизм переноса носителей заряда в мезопористом кремнии с сохранением прыжкового характера проводимости. При этом уменьшаются фононная частота колебаний решетки и концентрация заряженных ловушек, а также размер возможного прыжка, что, очевидно, связано с тем, что прыжки происходят по поверхности заряженного слоя пористого кремния.

Необходимо отметить, что все исследования проведены при малых дозах облучения, но при достаточно высоких энергиях дозы бетатрона. Дальнейшие исследования электрических и емкостных свойств структуры SiMP могут быть направлены на понижение мощности кванта гамма-излучения, что может способствовать применению SiMP в качестве фоточувствительных детекторов гамма-излучения, а также приборов с управляемой реактивностью и памятью переключения.

\section{Финансирование работы}

Исследование выполнено при финансовой поддержке Российского фонда фундаментальных исследований в рамках научного проекта № 18-07-00752а.

\section{Конфликт интересов}

Авторы заявляют, что у них нет конфликта интересов.

\section{Список литературы}

[1] Астрова Е.А., Витман Р.Ф., Емщев В.В., Лебедев А.А., Полоскин Д.С., Ременюк А.Д., Рудь Ю.В. // ФТП. 1996. T. 30. B. 3. C. $507-515$.

[2] Abbas J.K., Najam L.A., AuobSulaiman A.U. // Int. J. Phys. 2015. V. 3. N 1. P. 1-7.

[3] Биленко Д.И., Галушка Э.А., Жаркова Э.А., Сидоров В.И., Терин Д.В., Хасина Е.И. // Письма в ЖТФ. 2017. Т. 43. B. 3. C. $57-63$.

[4] Галушка В.В., Жаркова Э.А., Терин Д.В., Сидоров В.И., Хасина Е.А. // Письма в ЖТФ. 2017. Т. 43. В. 21. С. 72-77.

[5] Мотm Н., Девис Э. // Электронные процессы в некристаллических веществах. М.: Мир, 1982. Т. 1. С. 252.

[6] Биленко Д.И., Галушка Э.А., Жаркова Э.А., Мысенко И.Б., Терин Д.В., Хасина Е.И. // ФТП. 2011. Т. 44. В. 7. C. $984-986$.

[7] Поклонский Н.А., Вырко С.А., Забродский А.Г. // ФТП. 2008. T. 42. В. 12. C. $1420-1425$.

[8] Поклонский Н.А., Горбачук Н.И., Шпаковский С.В., Wieck A. // ЖТФ. 2010. Т. 80. В. 10. С. 74-82.

[9] Биленко Д.И., Белобровая О.Я., Галушка В.В., Жаркова Э.А., Мысенко И.Б., Терин Д.В., Хасина Е.И. // Нано- и микросистемная техника. 2009. № 10. С. 15-18.

[10] Зимин С.П. // ФТП. 2006. Т. 40. В. 11. С. 1385-1387.

[11] Вавилов С.И., Ухин Н.А. Радиационные эффекты в полупроводниках и полупроводниковых структурах. М.: Атомиздат, $1969.312 \mathrm{c}$. 